
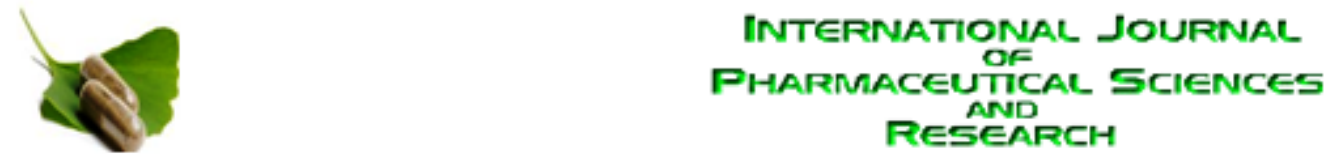

Received on 23 February, 2012; received in revised form 17 March, 2012; accepted 24 May, 2012

\title{
DEVELOPMENT AND VALIDATION OF SPECTROPHOTOMETRIC METHOD FOR THE ESTIMATION OF FLUCLOXACILLIN
}

Vipin Prakash ${ }^{* 1}$, Sharif Niroush Konari ${ }^{1}$, Gerad Suresh ${ }^{2}$

JDT Islam College of Pharmacy ${ }^{1}$, Calicut -673 012, kerala, India

College of Pharmacy, Madras Medical College ${ }^{2}$, Chennai, India

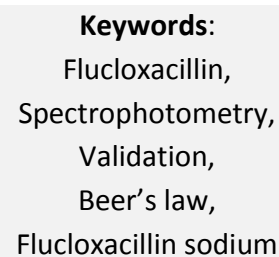

Correspondence to Author:

Vipin Prakash

Assistant Professor, JDT Islam College of Pharmacy, Calicut -673 012, kerala, India

\begin{abstract}
A new, simple, sensitive and reproducible spectrophotometric method has been developed for the estimation of Flucloxacillin in pure form. Method involves the determination of Flucloxacillin by dissolving in water and followed by measuring the absorbance at $273 \mathrm{~nm}$. The linearity was obtained in the concentration range of $100-300 \mu \mathrm{g} / \mathrm{ml}$. The suitability of method for quantitative analysis of Flucloxacillin was proved by validation. This method was extended to tablet formulation and there was no interference from excipients and diluents. This method has been statistically validated and is found to be precise and accurate.
\end{abstract}

INTRODUCTION: Flucloxacillin ${ }^{1}$ is chemically $(2 S, 5 R$, 6R)-6-(\{[3-(2-chloro-6-fluorophenyl)-5-methylisoxazole -4-yl] carbonyl\} amino)-3, 3-dimethyl-7-oxo-4-thia-1azabicyclo [3.2.0] heptane-2-carboxylic acid which is a narrow spectrum beta lactam antibiotic of the penicillin class. It is used to treat infections caused by susceptible gram-positive bacteria.

Unlike other penicillins, Flucloxacillin has activity against beta-lactamase- producing organisms such as Staphylococcus aureus as it is beta-lactamase stable used in the treatment of dyslipedimia and the prevention of cardio vascular disease.

Literature reviews ${ }^{2-8}$ revealed very few method of estimation for Flucloxacillin in bulk and formulation has been reported so far except HPLC ${ }^{9-10}$ in biological fluids.

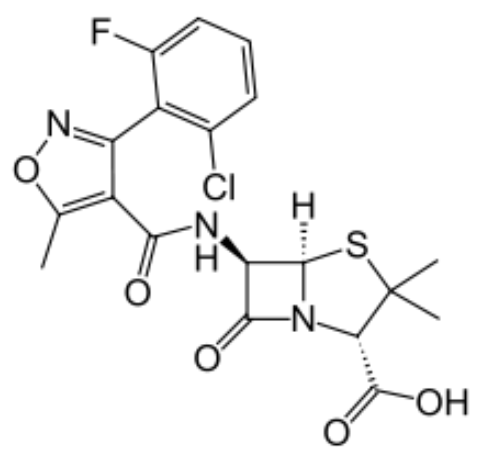

FLUCLOXACILLIN

MATERIALS AND METHODS: All the measurements were made using Shimadzu UV-visible double beam spectrophotometer with $1 \mathrm{~mm}$ matched quartz cells. All the solutions were freshly prepared using distilled water.

Preparation of Standard Stock Solution: It was prepared by dissolving $100 \mathrm{mg}$ of Flucloxacillin in water and diluted with distilled water in $100 \mathrm{ml}$ volumetric flask to produce $1000 \mu \mathrm{g} / \mathrm{ml}$. 
Absorption Maximum: The stock solution was suitably diluted with water so as to contain $100 \mathrm{mcg} / \mathrm{ml}$ of Flucloxacillin. This solution was subjected to scanning in UV region of $200-400 \mathrm{~nm}$ and found that Flucloxacillin exhibited maximum absorbance at about $273 \mathrm{~nm}$. The spectrum is recorded and shown in Figure 1.

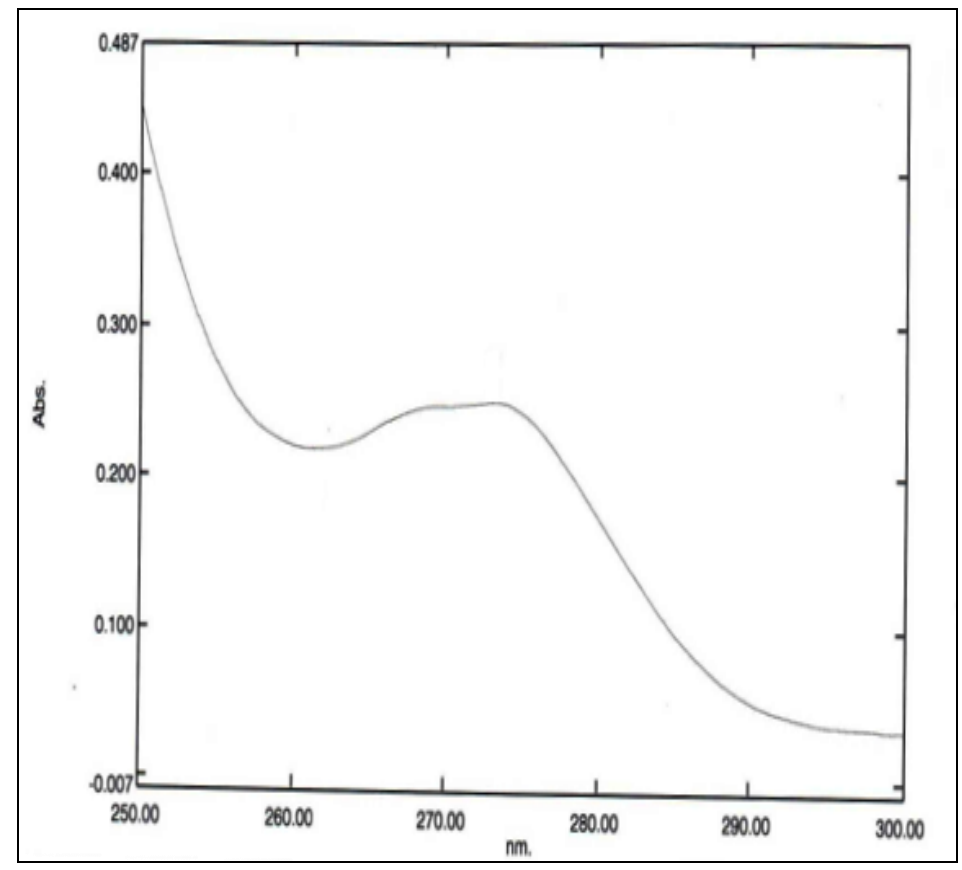

FIGURE 1: ABSORPTION MAXIMA OF FLUCLOXACILLIN

Linearity (Calibration Curve): Aliquots of 1, 1.5, 2, 2.5 and $3 \mathrm{ml}$ from standard stock solution were transferred to different volumetric flasks of $10 \mathrm{ml}$. The volume was adjusted to the mark with water gave a solution containing $100,150,200,250$ and $300 \mathrm{mcg} / \mathrm{ml}$ of Flucloxacillin. The absorbances were measured at $273 \mathrm{~nm}$ using water as blank and the calibration curve was constructed by plotting absorbance vs. concentration. It was found that the above concentration range obey Beer's law (Figure 2).

Precision: Repeatability, Intraday, Interday precision and optical characteristics of Flucloxacillin were calculated and shown in table 1.

Limit of Detection and Limit of Quantification: The limit of detection and limit of quantification were calculated as $20 \mu \mathrm{g} / \mathrm{ml}$ and $100 \mu \mathrm{g} / \mathrm{ml}$ respectively.

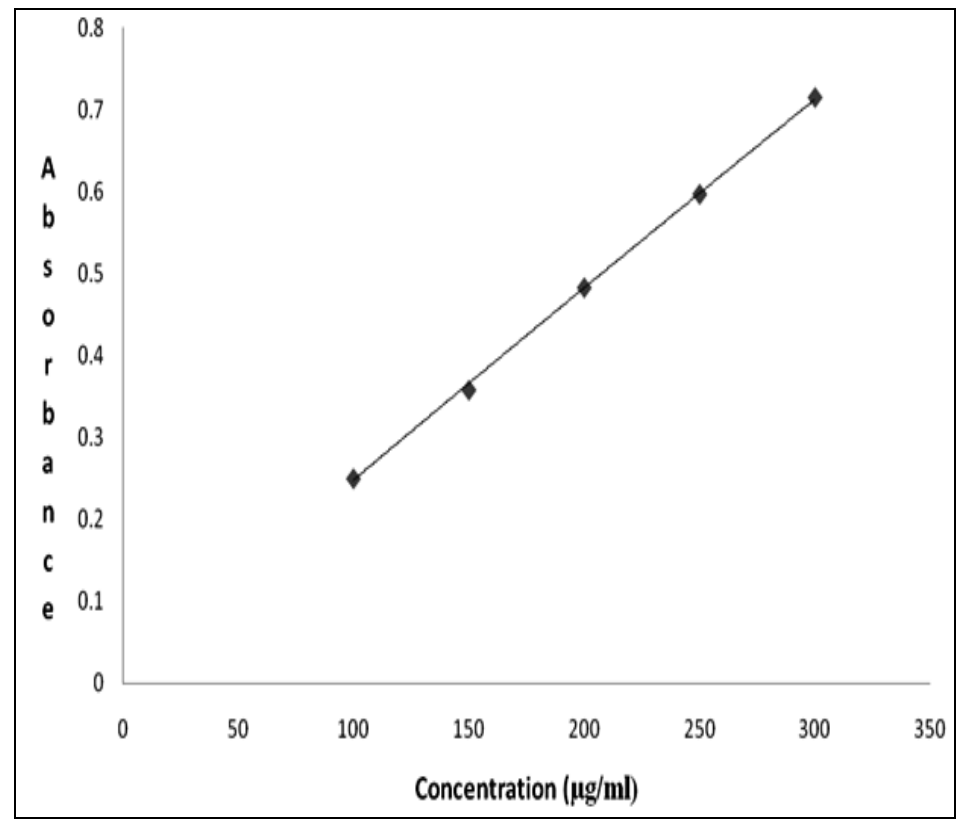

FIGURE 2: CALIBRATION GRAPH OF FLUCLOXACILLIN

TABLE 1: OPTICAL CHARACTERISTICS FOR FLUCLOXACILLIN

\begin{tabular}{|c|c|c|}
\hline Parameters & \multicolumn{2}{|c|}{ Flucloxacillin } \\
\hline$\lambda \max (\mathrm{nm})$ & $273 \mathrm{~nm}$ & \\
\hline Beer's law limits $(\mu \mathrm{g} / \mathrm{ml})$ & $100-300 \mu \mathrm{g} / \mathrm{ml}$ & \\
\hline LOD & $20 \mu \mathrm{g} / \mathrm{ml}$ & \\
\hline LOQ & $100 \mu \mathrm{g} / \mathrm{ml}$ & \\
\hline \multicolumn{3}{|l|}{ Precision* } \\
\hline Intraday & $0.3578 \pm 0.0003$ & $(\% \mathrm{RSD}=0.1062)$ \\
\hline Interday & $0.3413 \pm 0.0005$ & $(\% \mathrm{RSD}=0.1670)$ \\
\hline Repeatability & $0.3579 \pm 0.0006$ & \\
\hline Slope(m) & 0.002338 & \\
\hline Intercept (c) & 0.013 & \\
\hline Correlation coefficient $(r)$ & \multicolumn{2}{|c|}{0.9998} \\
\hline
\end{tabular}

*Each average of 3 determinations

RESULT AND DISCUSSION: Estimation of Flucloxacillin by UV spectrophotometry is done using water as solvent. The wavelength $273 \mathrm{~nm}$ was fixed for the estimation of Flucloxacillin. Different concentrations of Flucloxacillin were prepared from the stock solution and their absorbances were measured at selected wavelength. To study the validity ${ }^{[11-16]}$ of the method, Linearity, Repeatability, Intra and Inter day precision were carried out using same optimum conditions. The calibration curve was obtained in the range of 100-300 $\mu \mathrm{g} / \mathrm{ml}$ which obey Beer's law. The correlation coefficient was found to be 0.9998 . Precision studies were carried out as repeatability, Intraday and Interday assays. The Limit of detection (LOD) and Limit of quantification (LOQ) were found to be $20 \mu \mathrm{g} / \mathrm{ml}$ and $100 \mu \mathrm{g} / \mathrm{ml}$ respectively. 
CONCLUSION: The developed method is found to be simple, sensitive, accurate and precise. The proposed method can be used for routine analysis of Flucloxacillin formulation. The developed method was validated and the results proved that the method is reproducible and selective for the analysis of Flucloxacillin as single drug in bulk as well as in pharmaceutical formulations.

ACKNOWLEDGEMENT: The authors are thankful to Narsing Pharma (Surya Pharmaceuticals Ltd.) for providing gift sample of Flucloxacillin.

\section{REFERENCES}

1. http://en.wikipedia.org/wiki/Flucloxacillin

2. http://www.ncbi.nlm.nih.gov/pubmed/17341027

3. http://www.sciencedirect.com/science/article/pii/S073170850 4005540

4. Raj Pal Singh, Sally Ann Smesko, George H. Nancollas, Simultaneous determination of citrate and d-isocitrate in urine by isocratic ion chromatography Journal of Chromatography B: Biomedical Sciences and Applications, 1989 ;495: 239-244.

5. Pani grahi D,Sharma R,Development and validation of an RPHPLC method for simultaneous analysis of Dotraverine and omeprazole in tablet dosage form, Acta chromatographica, 2008;3:439-450.
6. Darji BH,Shah NJ, Patel AT and Patel NM,Development and validation of a HPTLC method for the estimation of Cefpodoxime proxetil.Indian J Pharm Sci. 2007; 69:331-333.

7. Prasad RK,Sharma R,Simultaneous estimation of Dotraverine and Nimusilide in tablet dosage form using RP-HPLC.Der Pharma chemical, 2010;2:141-151.

8. Shah M.N,Patel H.U,Patel C.N,Development and validation of spectrophotometric method for simultaneous determination of Cefpodoxime proxetil and ofloxacin in tablet,International $\mathrm{J}$ Pharm Sci research, 2012;3: 551-555.

9. Hao Liu, Hongwu Wang, V. Bruce Sunderland, An isocratic ion exchange HPLC method for the simultaneous determination of flucloxacillin and amoxicillin in a pharmaceutical formulation for injection, Journal of pharmaceutical and biomedical analysis, 2005; 37: 395-398.

10. Zhou $Q$, Ruan Z, Yuan $H$, Jiang $B, X u$ D, RP-HPLC analysis of flucloxacillin in human plasma: validation and application to a bioequivalence study, Pharmazie. 2007 ; 62:101-104.

11. Willard; Merrit; Dean; Settle: Instrumental method of Analysis; seventh edition; 75-83, 529.

12. Sharma B.K: Instrumental method of Chemical Analysis; $18^{\text {th }}$ edition, 1994; 3-12,114-119.

13. James W. Munson: Pharmaceutical Analysis, Modern Methods. Part A; 273.

14. Beckett A.H, Stenlake J.B: Practical Pharmaceutical Chemistry; $4^{\text {th }}$ edition; Part II. 275-357.

15. Indian Pharmacopoeia, Vol.III. New Delhi, The Controller Publication, Govt. of India,2010;1018.

16. British Pharmacopoeia, Vol.II. London. The British Pharmacopoeia Commission, 2010; 1546. 